九州大学学術情報リポジトリ

Kyushu University Institutional Repository

\title{
Reactions of Lead Ion in Mixtures of Silica and Magnesia
}

Ono, Hiroyuki

Graduate School of Bioresources and Environmental Sciences, Kyushu University

Wada, Shinichiro

Faculty of Agriculture, Kyushu University

https://doi.org/10.5109/9267

出版情報：九州大学大学院農学研究院紀要. 51 (2)，pp.437-440，2006-10-27. Faculty of Agriculture, Kyushu University

バージョン :

権利関係 : 


\title{
Reactions of Lead Ion in Mixtures of Silica and Magnesia
}

\author{
Hiroyuki $\mathrm{ONO}^{1 *}$ and Shin-Ichiro WADA \\ Laboratory of Soil Science, Division of Soil Science and Plant Production, Department of \\ Plant Resources, Faculty of Agriculture, Kyushu University, \\ Fukuoka 812-8581, Japan \\ (Received June 30, 2006 and accepted July 24, 2006)
}

\begin{abstract}
Lead $(\mathrm{Pb})$ is one of the toxic heavy metals found in many cases of soil pollution. Stabilization of lead contaminated soils by use of cement is the most popular way of remediation. However, in cases of multiple contaminations by lead and fluorine, magnesia may be superior to cement. To explore the possibility of immobilization of lead with magnesia, we mixed silica, magnesia and solutions of lead nitrate at a solid : solution ratio of $1 \mathrm{~kg}: 2 \mathrm{~L}$ and the reaction products were characterized by X-ray diffraction, Fourier transform infrared spectroscopy and sequential extraction of lead. The reaction of the mixture was alkaline just after mixing and became neutral after 5 days. After 5 days and on, only 0.0018 to $0.0051 \%$ of the lead in the mixture was extractable in water, $1 \mathrm{~mol} \mathrm{~L} \mathrm{MgCl}_{2}$ and $\mathrm{NaOAc}$, whereas 25 to $30 \%$ was extractable in $\mathrm{HCl}$. The XRD and FTIR spectra showed that lead was stabilized as carbonates and hydroxides.
\end{abstract}

\section{INTRODUCTION}

Lead $(\mathrm{Pb})$ is one of the heavy metals that have acute and chronic toxicity to humans. Lead is often incorporated in soils in mining and industrial activities and cationic lead is retained by soil colloids such as clay minerals and humic substances. The affinity of lead to these soil materials is so high particularly at high soil $\mathrm{pH}$ that its concentration in soil solution is usually kept low. However, it may be gradually released in soil solution as soil pH decreases, contaminates surface and ground waters and exerts harmful effect on humans via food web. Therefore, it is necessary to remediate lead-contaminated soils to prevent the diffusion of lead in the environment.

Immobilization of toxic substances, i.e. the reduction of bioavailability, is one of the ways to remediate contaminated soils. Stabilization by the use of cement is the most popular technique (Alpaslan and Yukselen, 2002; Halim et al., 2004; Jing et al., 2004). In cases of multiply contaminated contamination with heavy metals and fluorine, however, magnesia (MgO) could be used instead of cement. Magnesia incorporated in soils reacts with soil moisture to yield brucite. It helps to maintain soil $\mathrm{pH}>8$, which is favorable for retention of lead ions by soil colloids and precipitation of hydroxides and carbonates of lead (Jing et al., 2004). In addition, magnesia reacts with silicic acid to form phyllosilicates at normal temperatures (Hast, 1956; Henin, 1956; Temuujin et al., 1998), which may fix lead in their interlayer spaces or in octahedral sites.

In the present study, the reaction of lead in mixtures of silica and magnesia was investigated to explore the possibility of the use of silica and magnesia as stabilizing agents of lead in contaminated soils. Since there is

\footnotetext{
1 Laboratory of Soil Science, Division of Soil Science and Plant Production, Department of Plant Resources, Graduate School of Bioresources and Environmental Sciences, Kyushu University

* Corresponding author (E-mail: ono.h@kyushu-u.ac.jp)
}

no preceding research on the lead-silica-magnesia reactions, mixtures of silica and magnesia were mixed with an aqueous solution of lead but not with lead contaminated soils to ease the identification of reaction products.

\section{MATERIALS AND METHODS}

Reagent grade silica, magnesia and lead nitrate were used without purification throughout the study. Five grams of silica powder and $2.50 \mathrm{~g}$ of magnesia powders were mixed in six plastic bags and a $15.00 \mathrm{~mL}$ of $0.417 \mathrm{~mol} \mathrm{~L}^{-1}$ lead nitrate solution was placed in the bags. After mixing, the bags were heat-sealed. The bags were shaken several times a day and aged at room temperature. The suspensions were filtrated just after mixing, and after 1, 5, 10,20, and 30 days with membrane filters with a pore size of $0.45 \mu \mathrm{m}$.

The products collected on the filters were washed several times with deionized water. The washed products were air-dried and analyzed by powder X-ray diffraction (XRD) with $\mathrm{Cu}$ Ka radiation and Fourier transform infrared spectroscopy (FT-IR). The FT-IR spectra were recorded by diffuse reflectance method with the powder samples diluted with $\mathrm{KBr}$ powder at a ratio of about $1 \mathrm{mg}$ per $100 \mathrm{mg}$ of $\mathrm{KBr}$. The filtrates were analyzed for $\mathrm{Pb}$ and $\mathrm{pH}$ by atomic absorption spectrometry and glass electrode, respectively. The lability of lead in the reaction products was characterized by sequential extractions with water, $\mathrm{MgCl}_{2}, \mathrm{NaOAc}$, and $\mathrm{HCl}$. Water-soluble fraction was extracted by 6 hour-shaking with deionized water at a solid : liquid ratio of $1 \mathrm{~kg}: 10 \mathrm{~L}$. $\mathrm{MgCl}_{2}$-soluble fraction was extracted by 6 hour-shaking with $1 \mathrm{~mol} \mathrm{~L}^{-1} \mathrm{MgCl}_{2}$ solution at a solid : liquid ratio of $1 \mathrm{~kg}$ : $10 \mathrm{~L}$. NaOAc-soluble fraction was extracted by 6 hour-shaking with 1 mol L ${ }^{-1} \mathrm{NaOAc}$ (sodium acetate) solution at a solid : liquid ratio of $1 \mathrm{~kg}: 10 \mathrm{~L}$. Finally, $\mathrm{HCl}-$ soluble fraction was extracted by 2 hour-shaking with $1 \mathrm{~mol} \mathrm{~L}^{-1} \mathrm{HCl}$ solution at a solid : liquid ratio of $3 \mathrm{~kg}$ : $100 \mathrm{~L}$. At each extraction the clear extract was obtained by centrifugation at $2000 \mathrm{rpm}$ for 10 minutes and filtration. The lead concentration was measured by 
atomic absorption spectrometry.

In addition, silica-only and magnesia-only samples were prepared for comparison and analyzed in the same way.

\section{RESULTS AND DISCUSSION}

Fig. 1 shows the trend in suspension $\mathrm{pH}$ during reaction. The $\mathrm{pH}$ in the silica-only system ranged from 4.2 to 4.5 , whereas the $\mathrm{pH}$ in the magnesia-only system decreased from 10 to about 7 in a day after mixing and fluctuated around 7.5 thereafter. The pattern for the silica-magnesia system resembled that for magnesia-only system.

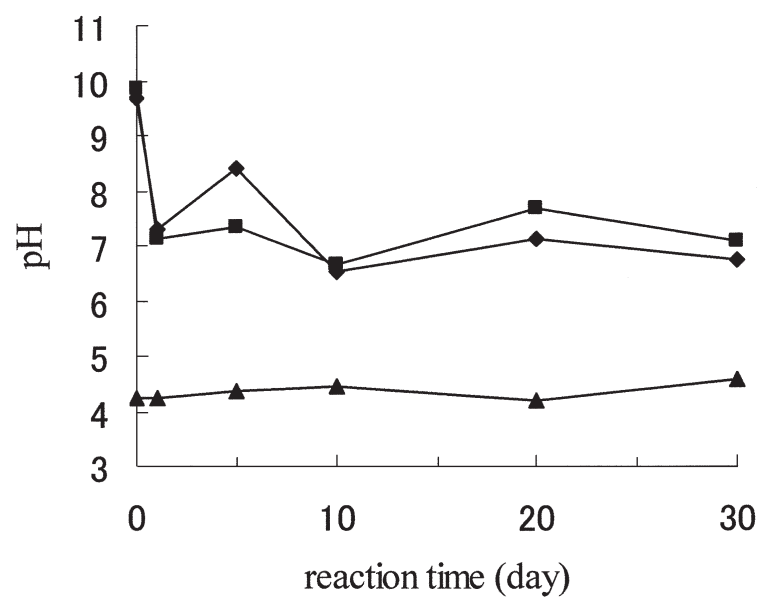

Fig. 1. Change in $\mathrm{pH}$ during reaction. $\boldsymbol{\Delta}$ : silica-only, $\boldsymbol{\square}$ : magnesia-only, : silica-magnesia system.

Fig. 2 shows the lead concentration in the filtrates from the magnesia-only and silica-magnesia systems. The lead concentrations in the filtrate from the silica-only system were well above $85.8 \mathrm{mg} \mathrm{L}^{-1}$ throughout the experiment and were not plotted in Fig. 2. The lead concentration in the solution added to the silica, magne-

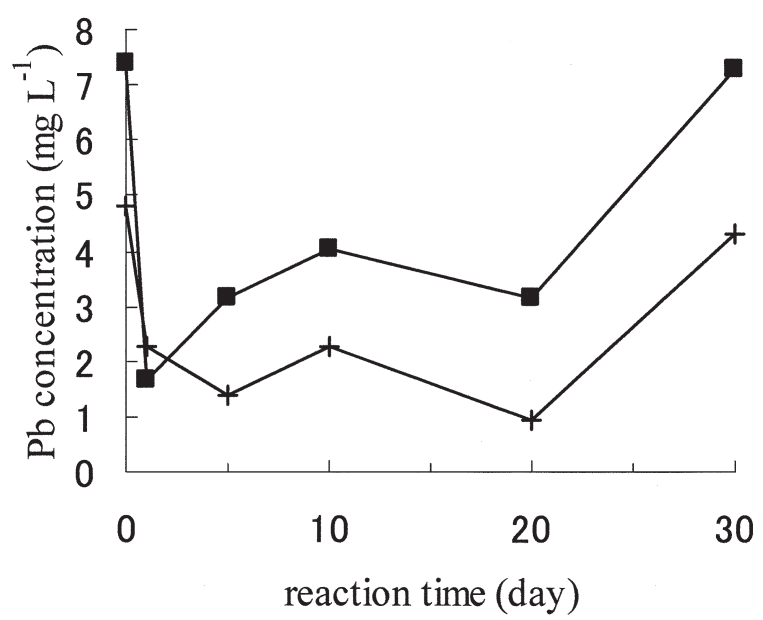

Fig. 2. Metal concentration in reaction solution. $\square$ : magnesia-only, + : silica-magnesia system. In silica-only system, metal concentrations were over $0.41 \mathrm{~mol} \mathrm{~L}^{-1}$ throughout the reaction period. sia and their mixture was $0.417 \mathrm{~mol} \mathrm{~L}^{-1}$, i.e., $86.3 \mathrm{~g} \mathrm{~L}^{-1}$. The result shown in Fig. 2 shows that magnesia and silica-magnesia mixture are effective in reducing solubility of lead. The lead concentration was significantly lower in the silica-magnesia system than in magnesia-only system probably because the lead was retained as surface complexes at the silanol groups of the silica.

The XRD patterns of the solid materials separated by filtration and air-drying are shown in Figs. 3 and 4 . Fig. 5 shows FTIR spectra of some of the recovered materials. Both the XRD pattern and FTIR spectrum of the solid from the silica-only system indicate that no significant structural change occurred in the silica. The absence of the diffraction peaks from crystalline lead compounds indicate that lead was mostly adsorbed on the silica surface forming surface complexes. On the other hand, the solid material from the magnesia-only system gave sharp diffraction peaks from magnesia hydrated immediately after mixing with the solution to form magnesia, brucite, basic lead carbonate $\left(\mathrm{Pb}_{3}\left(\mathrm{CO}_{3}\right)_{2}\right.$ $\left.(\mathrm{OH})_{2}\right)$ and basic lead nitrate $\left(\mathrm{Pb}_{3}\left(\mathrm{NO}_{3}\right)(\mathrm{OH})_{5}\right)$ (Fig. 3). Magnesia and basic lead nitrate were disappeared after 1 day. The intensity of the peaks from basic lead carbonate increased in 1 day and then decreased in 5 days, and persisted for 30 days. The intensity of the peaks from brucite increased in 5 days and persisted thereafter. The sharp peaks $(\mathrm{d}=8.06 \sim 8.08,3.25 \sim 3.23,2.91,1.59$, $7.12,5.51 \AA$ ) appeared after 5 days and increased up to after 10 days, then gradually decreased. On FT-IR spec-

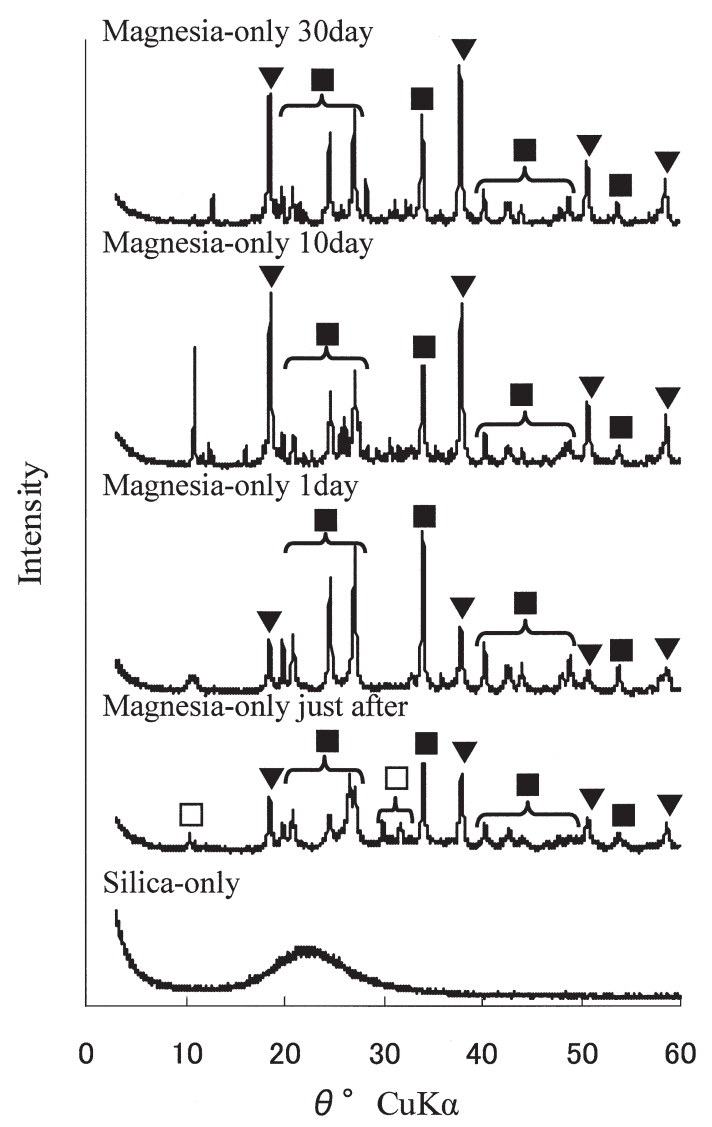

Fig. 3. XRD patterns of reaction products on silica-only and magnesia-only systems. $\boldsymbol{\nabla}$ : brucite, $\square$ : basic lead nitrate, basic lead carbonate. 

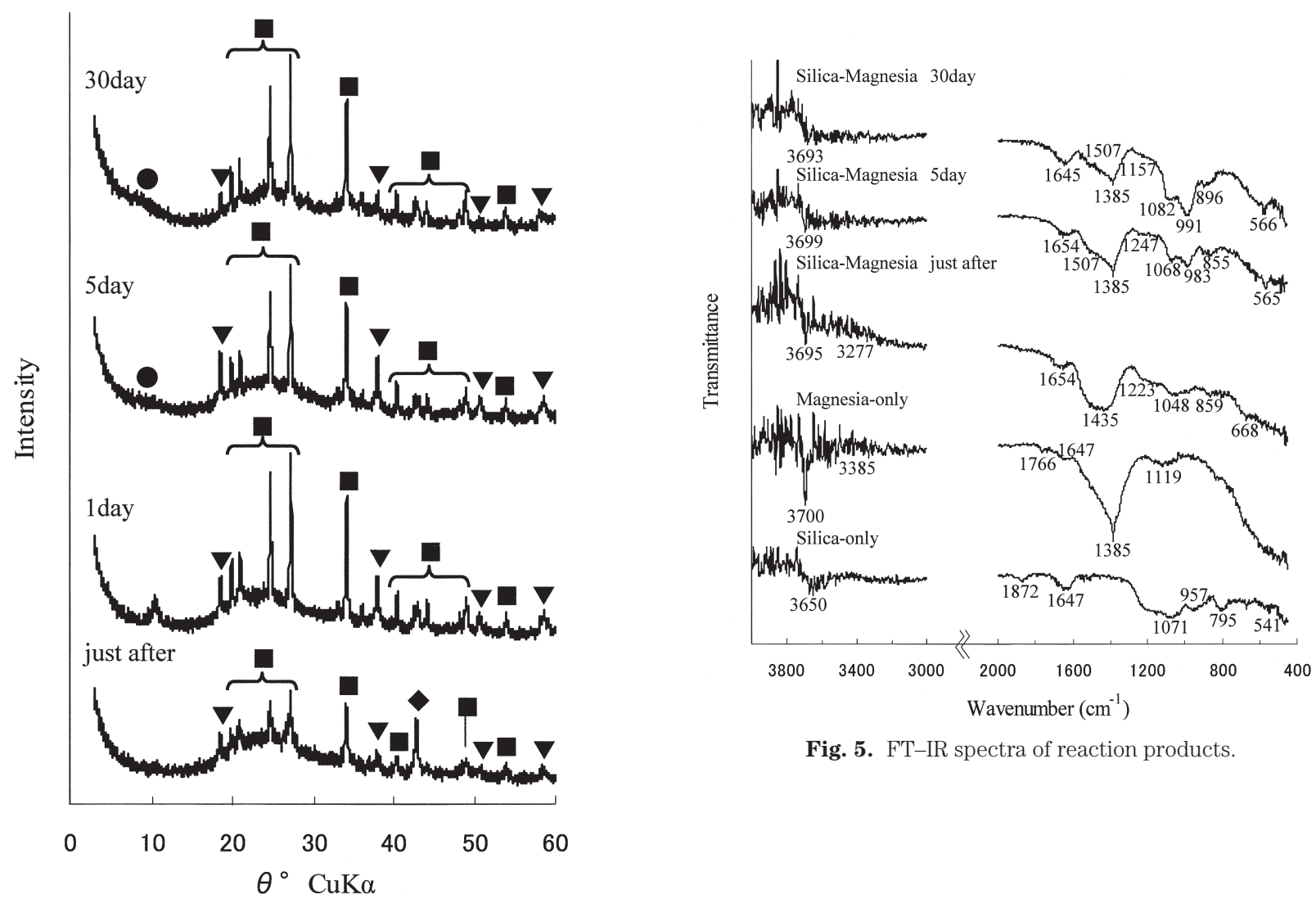

Fig. 5. FT-IR spectra of reaction products.

Fig. 4. XRD patterns of reaction products on silica-magnesia system. $\bullet$ : magnesia $\boldsymbol{\nabla}$ : brucite, $\mathbf{\square}$ : basic lead carbonate, : magnesium phyllosilicate

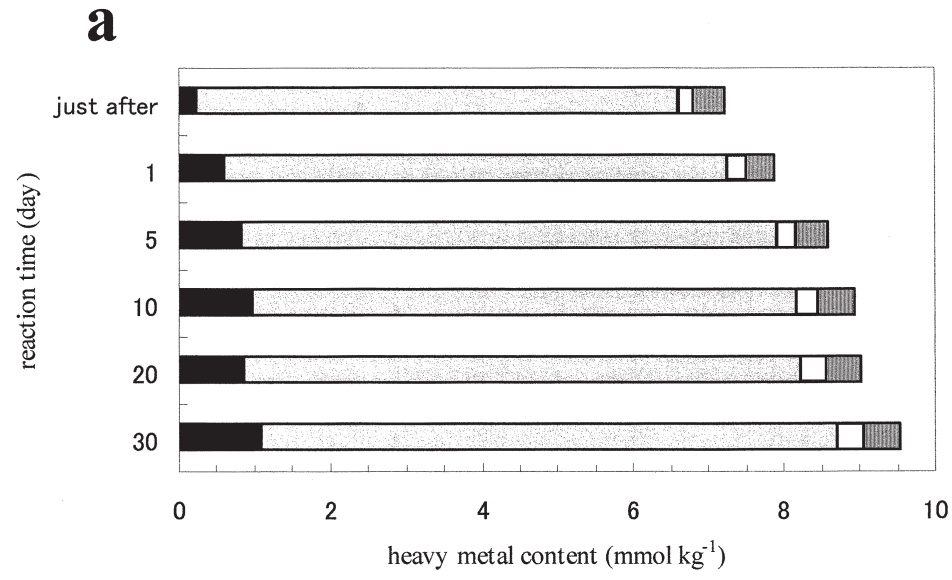

water-extract 口 $1 \mathrm{M} \mathrm{MgCl} 2$-extract $\square 1 \mathrm{M} \mathrm{NaAc-extract}$ 四 1M HCl-extract

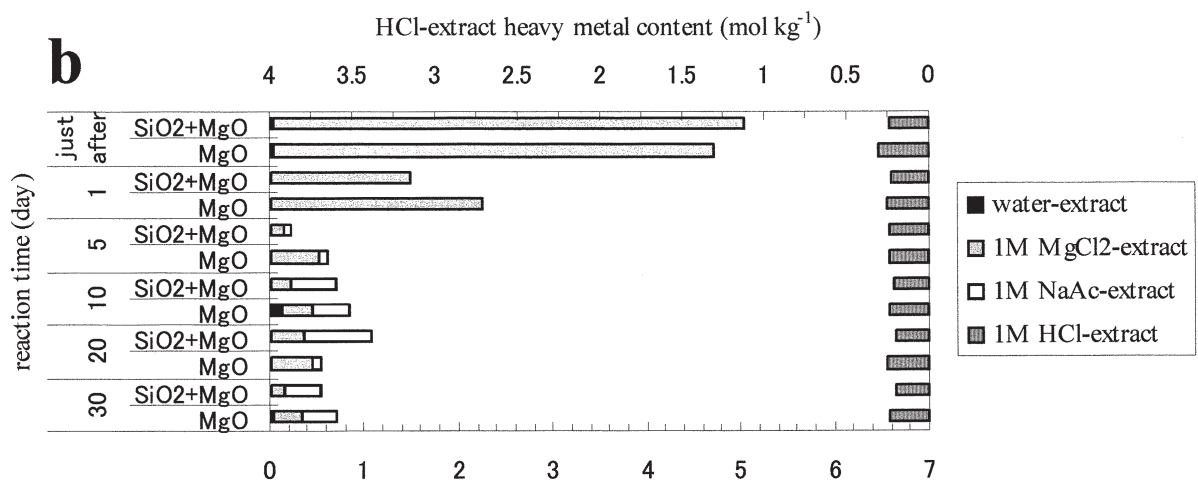

Fig. 6. Distribution of heavy metal in four fractions. (a) silica-only, (b) magnesia-only and mixture of silica and magnesia. 
tra, the broad peaks at $858 \sim 862,1080 \sim 1083,1650$, 1768 , and $3520 \mathrm{~cm}^{-1}$ and sharp peaks at 1384 and $3700 \mathrm{~cm}^{-1}$ were noticed (Fig. 5).

The solid material from silica-magnesia system gave diffraction peaks from brucite and basic lead carbonate just after mixing (Fig. 4). The intensity of the peaks from brucite increased in 1 day and decreased gradually thereafter. The intensity of the peaks from basic lead carbonate also increased gradually in 20 days. Those for basic lead carbonate deceased in 30 days. In addition, diffuse band at around 4.50, 3.56, 2.58 2.60 and $1.55 \AA$ appeared after 5 days and their intensity increased gradually, suggesting that poorly-ordered phyllosilicate formed in the silica-magnesia system. On FT-IR spectra, the intensity of the peaks at 1063 1067 and $3700 \mathrm{~cm}^{-1}$ decreased, while the broad peak centered at $983 \mathrm{~cm}^{-1}$ increased gradually (Fig. 5). The peaks at 1063 $\sim 1067 \mathrm{~cm}^{-1}$ persisted after 30 days.

The results of the sequential extraction were graphically presented in Fig. 6. Fig. 6a shows that about 0.509 to $0.655 \%$ of the loaded $\mathrm{Pb}$ was extracted from the silica-only system by the 4 extracting reagents including water. It is puzzling that the amount of each fraction increased on aging. It is unlikely that lead carbonate formed in the silica-only system because the solution $\mathrm{pH}$ was mostly below 5, the $\mathrm{MgCl}_{2}-$, $\mathrm{NaOAc}-$ and $\mathrm{HCl}-$ extractable fraction of lead probably came from surface complexes having relatively low stability. The

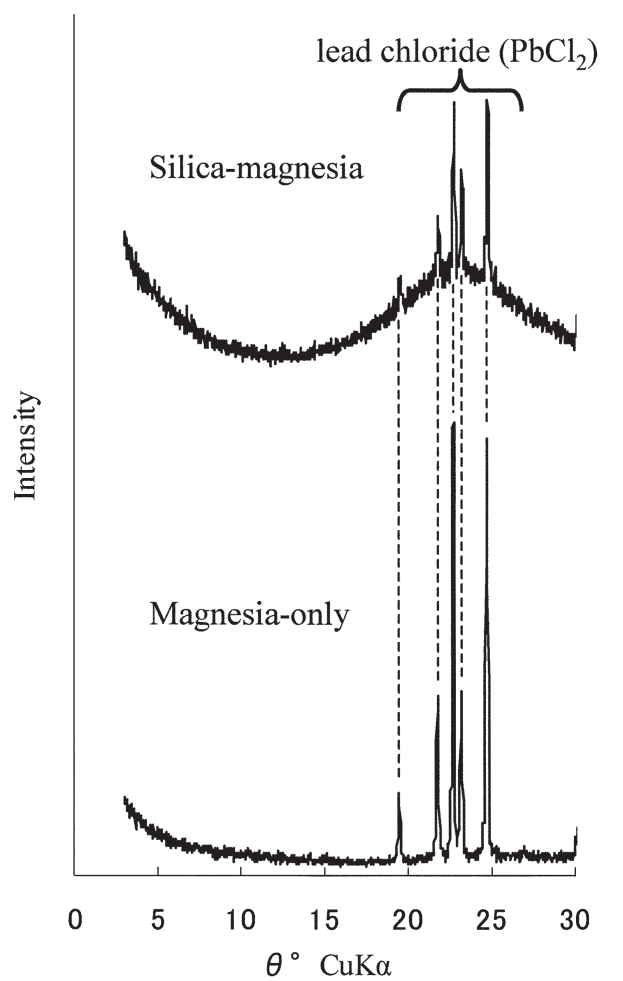

Fig. 7. XRD patterns of the residues of $\mathrm{HCl}$-extraction on magnesia-only and silica-magnesia systems. results suggest that the silica is effective for reducing the solubility of lead even without $\mathrm{pH}$ adjustment.

The comparison of Fig. 6a and Fig. 6b shows that the amount of water-, $\mathrm{MgCl}_{2}-$ and $\mathrm{NaOAc}-$ extractable lead was significantly lower in magnesia-only and silica-magnesia systems whereas that of $\mathrm{HCl}-$ extractable lead was by far the higher. Approximately 25 to 30\% of the loaded lead was extractable in $\mathrm{HCl}$. This is probably a significant part of the loaded lead was transformed into basic lead carbonate and basic lead nitrate, which are unstable in acidic solutions. It was noticed that white powdery material remained after the $\mathrm{HCl}-$ extraction of magnesia-only system. The XRD patterns from the residues of the magnesia-only and silica-magnesia systems after $\mathrm{HCl}$ extraction are shown in Fig. 7. The XRD patterns indicate that the residues after $\mathrm{HCl}$ extraction contained lead chloride, suggesting that the extracted lead mostly precipitated as lead chloride.

\section{CONCLUSIONS}

Lead nitrate loaded to a silica-magnesia mixture was stabilized mostly as lead carbonate and basic lead nitrate, and partly as surface complexes on silica. XRD patterns indicated that poorly ordered phyllosilicate formed in the silica-magnesia mixtures aged 5 days or longer but it was unlikely that lead cation was fixed as interlayer or octahedral cation of the silicate.

The results of analysis into products and filtrates show that most of lead cations precipitated as carbonates and hydroxides when magnesia includes. And, the results of sequential extraction indicated that magnesia reduces aqueous solubility and cation exchange for lead, whereas production of lead chloride by $\mathrm{HCl}-$ extraction showed the little stability of lead precipitates in acid solutions. So, magnesia seems to have possibilities to immobilize lead cations, but less persistent of immobilization than the cement.

\section{REFERENCES}

Alpaslan, B. and M. A. Yukselen 2002 Remediation of lead contaminated soils by stabilization/solidification. Water, Air and Soil Pollu. 133: 253-263

Halim, C. E., R. Amal, D. Beydoun, J. A. Scott, and G. Low 2004 Implications of the structure of cementitious wastes containing $\mathrm{Pb}(\mathrm{II}), \mathrm{Cd}(\mathrm{II}), \mathrm{As}(\mathrm{V})$, and $\mathrm{Cr}(\mathrm{VI})$ on the leaching of metals. Cem. Concr. Res., 34: 1093-1102

Hast, N. 1956 A reaction between silica and some magnesium compounds at room temperature and at $+37^{\circ} \mathrm{C}$. Ark. Kemi., 9: $343-360$

Henin, S. 1956 Synthesis of clay minerals at low temperatures. Clays Clay Miner., 4: 54-60

Jing, C., X. Meng and G. P. Korfiatis 2004 Lead leachability in stabilized/solidified soil samples evaluated with different leaching tests. J. Hazard. Mater. B, 114: 101-110

Temuujin, J., K. Okada and K. J. D. MacKenzie 1998 Role of water in the mechanochemical reactions of $\mathrm{MgO}-\mathrm{SiO}_{2}$ systems. J. Solid State Chem., 138: 169-177 